\title{
Compost Soil Amendment: An Approach to Enhance Crop Productivity by Improving Soil Physiology
}

\section{Ieshita Pan*}

Department of Biotechnology, Saveetha School of Engineering, Saveetha Institute

of Medical and Technical Sciences, Chennai, Tamil Nadu, India

*Corresponding Author: Ieshita Pan, Department of Biotechnology, Saveetha School of Engineering, Saveetha Institute of Medical and Technical Sciences,

Chennai, Tamil Nadu, India.
Received: December 15, 2021

Published: January 31, 2022

(C) All rights are reserved by Ieshita Pan.

\section{Abstract}

An excellent alternative for improving soil quality is composting, where intricate organic matter is converted into the simple stable end product through microbial decomposition. Although mainstream research has focused on environmental impacts, compost production and use, few reports point out key contributors and their mechanism to improve soil. In the past, the use of organic supplements to control soil biological remediation has been successful, but humus has been required as an external supplement to increase fertility. This study summarizes the role of key contributor in composting to improve crop productivity. In order to identify that, various soil quality indicators are examined. In all cases (1) The humic acid concentration is directly proportional to soil nutrient contents, NPK, available nitrogen, phosphorus, potassium, and other parameters such as soil enzymes, CEC, water holding capacity, and microbial colonization. (2) The external addition of humus increases production costs. However, process modification either by microbes or the addition of mineral additives/fillers during composting is economical and can improve the humification process by preventing nitrogen loss. The humus-rich, inexpensive use of compost protects the quality of the environment because it breaks down solid waste. (3) To make a long profit from the compost, the product must be mature, stable, and free from pathogens. Recent development has not only limited itself to microbial degradation in order to obtain high quality compost, but has also produced commercial formulations. Almost all solid organic wastes are enriched with lignocellulose, and microbial inoculation allows about $30 \%$ improved deterioration compared to non-inoculated treatment to obtain humus-like substances. This review article discusses about the easiest way to enrich the soil with humus through microbial degradation of lignin, hemicelluloses and cellulose in bio-organic waste to form compost, promote soil fertility and at the same time keep the environment clean and healthy. Not only soil fertility but also the development of high quality, nutritious food is urgently needed for new cultivation methods. Instruction to maintain the international economy and to protect the environment, soil amendment with compost is the necessity as it correlates with humus enrichment.

Keywords: Composting; Fertility; Humification; Maturity; Sustainable Agriculture; Waste Management

\section{Introduction}

In the most cases, the green revolution technologies involved greater exploitation of synthetic agricultural substances such as fertilizers and insect killers with the addition of nutrient sensitive, high-yielding crops that heightened the yield per hectare [1].
However, in the last decade, there have been signs of a decline in productivity and also in the level of production. It is reported that intensive cultivation patterns, climate, and inadequate land management are the main causes of organic matter degradation in the soil leading to stagnation in crop yields [2]. In addition, traditional 
farming practices also exacerbate the situation and cause severe nutrient shortages. Due to insufficient organic matter input, soil microbes tend to be less and less diverse leading to imbalances in the soil nutrient cycle [3]. Although chemical agriculture meets the nutritional needs of a crop, it is not favorable to the natural environment of the soil, resulting in difficult soil that is polluted with inorganic ions. Constant chemical usage alters soil $\mathrm{pH}$ and generates toxicity to the plants. However, for crop productivity, skillful utilization of chemical fertilizers is also necessary [4]. Due to the current development of inorganic fertilizer application, almost all sites are now polluted with organic impurities and their numbers are increasing proportionately [5]. Therefore many of these unhygienic sites necessitate active clean-up immediately to abolish toxic substances. The evaluation costs and remediation measures for these polluted sites are exceptionally very high. An inexpensive substitution is therefore now necessary. Thus, bioremediation is taken up as a potential, profitable alternate [6]. It initiates biostimulation by adding nutrients, fertilizers, and organic components, and bio-augmentation by adding microbes, activated sludge or compost. Compost has not only been used on a large scale for biodegradation to remove toxins since the early 1980s. In addition, soils polluted with chlorophenol, tar oils and mineral oils dominate the pollution with polycyclic aromatic hydrocarbons [7]. Not only is it an effective method, some studies suggest process failures due to the low productivity of bio-stimulation techniques on original landfills.

In particular, the processing of compost is seen as promising not only for biological soil bioremediation, but also for soil improvement [6]. Compost is a valuable source of humic acid, a group of molecules that help plants provide water and nutrients by preventing them from being leached out. A high humic acid content could dramatically increase crop yields [8]. The root area can become nutrient poor if there is a scarcity of humic acid or mycorrhizal fungi. Compared to the plant root, mycorrhizae can collect nutrients through their hyphae microtubes, which can expand much further into the soil to collect these elements even outside the zone of depletion. Humus is even more crucial for plant nutrient uptake if healthy mycorrhizae are absent. Nevertheless, compost improves the plant nutrient status of the soil, keeps the organic components of the soil at a higher level than inorganic fertilizers, restores soil physiology, her WHC, support valuable microbial colonization, reduce plant pathogens, set up inexpensive disposal methods, reduce the chemical fertilizers need and control erosion, water penetration and nutrient uptake [4]. Since the root has a negative charge, positively charged ions are easily absorbed by a plant root. Humic matter (both humic and fulvic acid) improves the transfer of micronutrients into the plant's circulatory system by accepting positive ions that are attracted not only to the root but also to the hyphae microtubes of the mycorrhizae [9]. Compared to humic acid the accumulated negative charge on the root is higher, so micronutrients are successfully taken up and absorbed by the plant's circulatory system. Some of them dissociate from the humic acid molecule when penetrating the root membrane. Since humic substances can chelate, the availability of these cations $\left(\mathrm{Mg}^{2+}, \mathrm{Ca}^{2+}\right.$ and $\left.\mathrm{Fe}^{2+}\right)$ for plants is increased. Compared to sewage sludge, NPK fertilizer or other organic fertilizers, the nutritional value of compost is found better with increased harvest yields. Recycling solid waste and returning nutrients to the soil is the fundamental desire to make the environment healthier. Off the total applied nitrogen [N], only $2-15 \%$ nitrogen yield of the plants could be achieved [10].

Lignocellulose, a key factor in organic waste, is the most stable and stubborn organic carbon fraction that not only restricts rapid composting, but also limits humus formation [11]. Jindo., et al. [12] and Zhang., et al. [13] found that biochar can promote the breakdown and humification of organic matter when added to composting pig manure and sewage sludge. In addition, Jurado., et al. [14] noticed that microbial inoculums could allow 21-28\% deterioration in lignocellulose compared to non inoculated treatment of tomato plants and composting of pine chips. Humic-like substances were obtained from the breakdown of homogeneous raw materials containing lignocellulose. However the formation of humic substance during composting is one of the complicated, least understood but fascinating mechanisms. There are several ways for the formation of humic substances when plant and animal residues are rotting in the soil, the most important of which are summarized in (Figure 1). Although in practice all four routes must be considered as key mechanisms for the synthesis of humic and fulvic acids in nature, including sugar-amine condensation, only one is operated at a time. According to the classical theory, the formation of humic acid was mainly achieved from modified lignins. However majority of researchers today favor a mechanism involving quinones in which microbial oxidase plays the key role. Ligninolytic fungi first attack simple carbohydrates, parts of the protein and cellulose in the medullary rays, the cambium, and the cortex of plants debris 
to initiate decomposition [14]. The cellulose in the xylem is broken down by aerobic myxobacteria. Polyphenols synthesized by the myxobacteria are oxidized to quinones by polyphenol oxidase enzymes, which then react with $\mathrm{N}$-compounds to form brown humic substances. Pseudomonas sp. was the key player in this conversion. In composting Bohacz [15] found a significantly high correlation of the number of nutritionally-specialized groups of fungi responsible for complex ligno-cellulose biodegradation with an increase in respiratory activity and dehydrogenase activity. This review article discusses the choice of compost as a soil improver because of its potential to increase humus levels in the soil through the microbial degradation of lignocellulose in the bio-organic waste, to manage solid waste and improve plant growth.

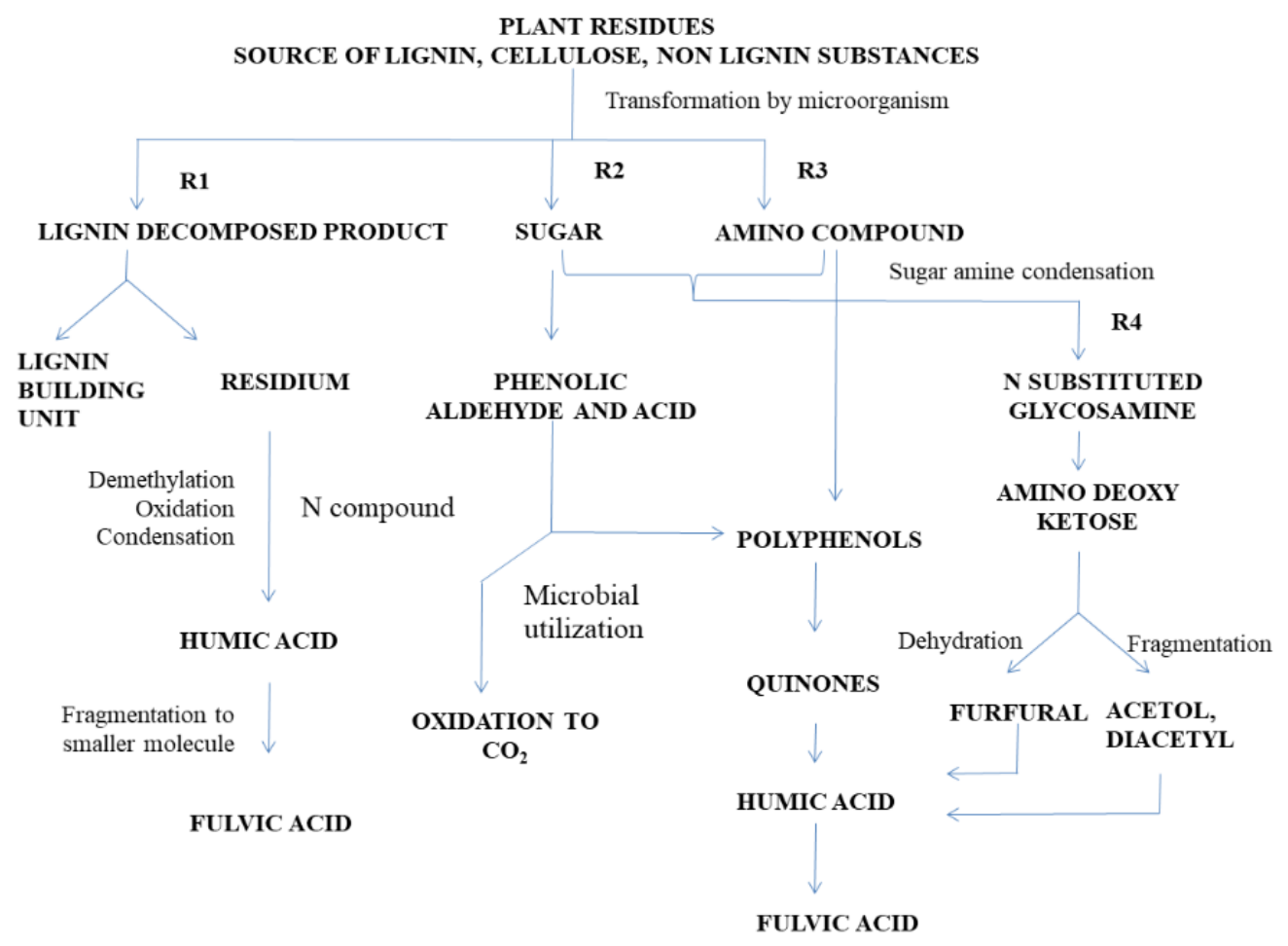

Figure 1: Schematic representation of the conversation of solid organic waste to Humic acid. R1-R4 represents all the routes through which microbes degraded the complex material and generate humic substances.

\section{Composting and microbial diversity}

Current research has mainly focused on improving soil quality using microflora in order to change its physicochemical properties. However, few studies have looked at the role of humic acid on soil microflora. This went hand in hand with a reduction in carbohydrate, hemicellulose and cellulose and increased humification [16]. Humification is an index of compost maturity and serves as a key factor for assessing the characteristics of soil physiology, ionic components, and productivity [1]. A previous study found that one more sustainable step in increasing plant production is to add organic fertilizers, which are a rich source of microorganisms that promote plant growth. They influence plant growth either directly by improving nutrient uptake, fixing atmospheric $\mathrm{N}_{2}$, solubilizing inorganic $\mathrm{P}$, improving the root surface, or indirectly by producing hormones, and suppressing pathogens [17]. Initially, plant growthpromoting rhizobia were the inoculum of choice, but now all potential organisms are being added to achieve the required growth. At the top, however, are bacteria of the genera Escherichia, Kleb- 
siella, Aeromonas, Alcaligenes, Bacillus and Enterococcus. Instead, some common fungal communities, e.g. Cladosporium, Aspergillus, Mucor, Rhizopus, Penicillium, with Micromonospora as Streptomyces are the predominant actinomycetes. Trichoderma viride and Pleurotus sajor-caju also take an active part in the decomposition process $[3,15]$. The mesophilic organic acid producing bacteria such as Lactobacillus sp. and Acetobacter sp. was initially present, whereas Bacillus sp. and Actinobacteria, become dominant in later stages. In the second phase, thermophilic actinomycetes of the species Faenia rectivirgula, Saccharomonospora viridis, Streptomyces thermoviolaceus, Thermoactinomyces thalpophilus, T. vulgaris and Thermomonospora cuvata predominate $[14,18]$.

This bio-solid to compost conversion with diverse micro flora is a three phase processes that is summarized in (Table 1). During the first phase with a simultaneous increase in temperature, the carbon dioxide content is also increased, but the raw material is reduced due to the breakdown of carbohydrates and proteins (Figure 2). This is due to the effect of mesophilic organisms [11]. In the second phase of composting, the temperature rose from $45^{\circ} \mathrm{C}$ to around $70^{\circ} \mathrm{C}$ and thermophiles replaced the mesophiles [18].
The high degree of pathogen removal took place in parallel [11,17]. As the temperature dropped, the third phase of composting began with mesophile repopulation. The rhizosphere soil microbes that maintain the ecology of the rhizosphere are sensitive to environmental changes. Inorganic fertilizers alter the soil's microbial community and its functional activities. On the contrary, due to the presence of humic acid, Firmicutes, Basidiomycota and Mortierellomycota predominate in compost soil, increasing soil nutrient levels, soil enzyme activity and microbial diversity. Compost production through microbiological degradation is easily digestible to become a stabilized end product and suppress plant diseases [11]. For more environmentally friendly cultivation methods, they can partially replace other expensive agrochemicals in order to meet the increasing requirements. Since the activity of the soil enzymes is an indicator of the high metabolism in the soil, it can also indicate nutrient uptake, utilization and plant growth. The appearance of the compost material changes from dark brown to black with reduced particle size, earth-like texture, increased humus content and ion exchange capacity indicating its completion [19]. Compost, with its key component humic acid, directly increases plant productivity and makes the soil healthier.

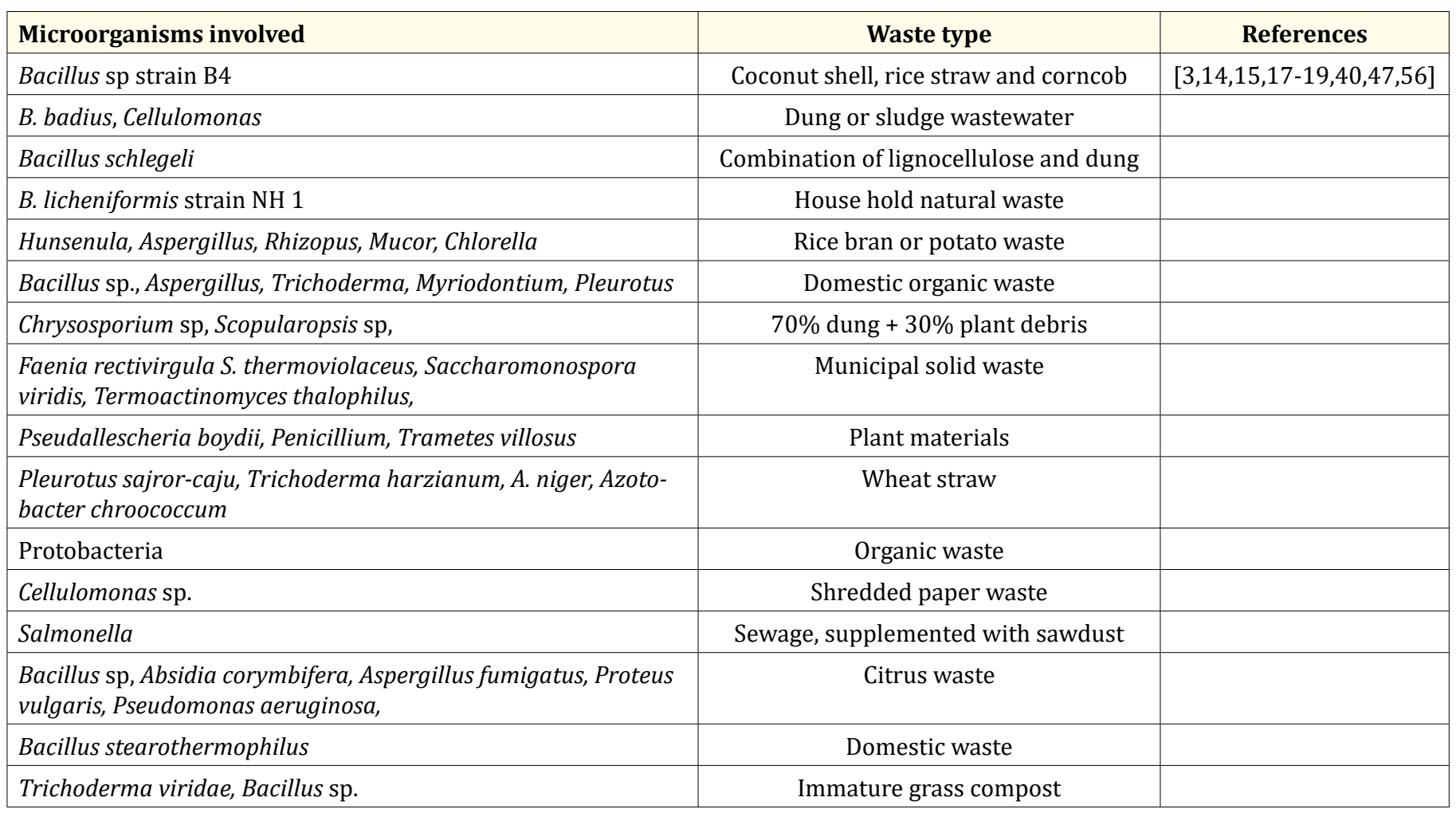

Table 1

Citation: Ieshita Pan. "Compost Soil Amendment: An Approach to Enhance Crop Productivity by Improving Soil Physiology". Acta Scientific Microbiology 5.2 (2022): 88-103. 
RAW MATERIAL

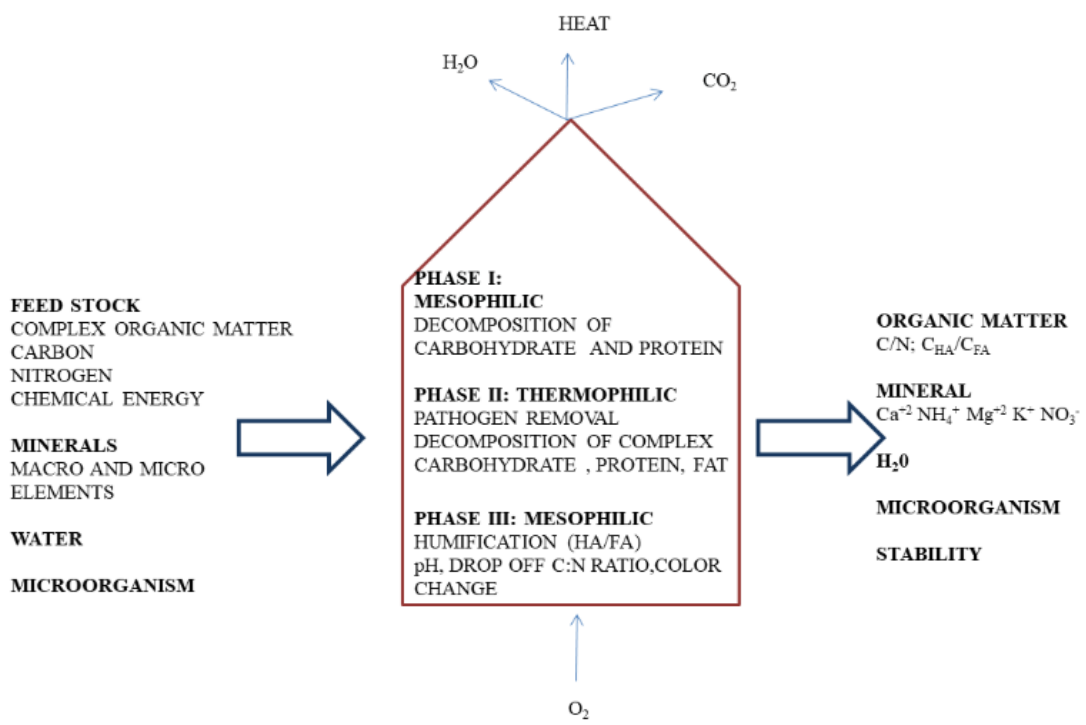

Figure 2: Schematic representation of compost formation. From various raw materials mature compost formation occurred by the colonization of microbial community which is a three phasic biodegradation process.

\section{Determination of compost maturity}

Using compost is an inexpensive way to curb agronomic problems, and its soil application is a convenient way to restore soil fertility as well as crop productivity. However, when unstable compost is spread on the land the crop yield decreases due to the increase in the production of phytotoxic complexes, insect pollution, insufficient nitrogen and oxygen concentrations and the formation of unpleasant odors. Therefore, attention is drawn to the assessment of the compost maturity in order to determine the process completion [20]. No technique or method alone can be used successfully to assess biological stability and maturity of compost. On the other hand, the integrated use of various parameters, i.e. physical, chemical and biological parameters, a more comprehensive understanding of compost maturity. In order to get the maximum benefit from the application of compost in field trials, several other indexes are used to assess quality. Color, odor, $\mathrm{pH}, \mathrm{C} / \mathrm{N}$ ratio, and ionic components dominated among them. In the last ten years, however, these restrictions were not considered sufficient to assess the degree of maturity of compost [1,20]. Now analyzes the degree of self-healing ability, organic matter (OM), cation exchange capacity (CEC), nutrient content, phytotoxicity test, germinaton index (GI), temperature drop, moisture content, conductivity, ionic strength and the presence of potential pathogens such as Salmonella sp. Actinobacteria, coliform bacteria, etc. are the parameters that are used to prove the compost quality and maturity [21]. Physical properties include particle size, texture, particle density, bulk density, dry matter content and the content of non-compostable debris (stone, plastic and glass) also provides additional information.

The degree of maturity was also determined by calculating the humification index using the humic and fulvic acids concentration, UV-Vis spectroscopic measurements, FTIR, and 13C NMR. Amir., et al. [22] found that the analysis of the E4/E6 ratios (E, the optical density of the test solution with 6 and 4 attached specified 664 $\mathrm{nm}$ and $472 \mathrm{~nm}$ ) and the ratio of $\mathrm{C}_{\mathrm{HA}} / \mathrm{C}_{\mathrm{FA}}$ determined the functional groups present in compost with its level of maturity. Grube., et al. [23] proposed the method to determine the concentration of cadmium $\left(\mathrm{Cd}^{+2}\right)$, cobalt $\left(\mathrm{Co}^{+2}\right)$, zinc $\left(\mathrm{Zn}^{++}\right)$, nickel $\left(\mathrm{Ni}^{+2}\right)$, and lead $\left(\mathrm{Pb}^{+2}\right)$ to check heavy metal exposure. Phytotoxicity study, seed germination, existence of the pathogen and assessment of plant growth are other methods routinely performed to determine its biological stability [1]. The product should always be analyzed for complete elimination of pathogenic microorganisms like Enterococcus faecalis, Clostridium sp. before its field application [18]. Fertilizers from municipal waste are not only enriched with mesophilic bacteria, but also with yeasts and filamentous fungi, with bacterial spores, and also with Salmonella and Shigella contaminanants. However, numerous other pathogens of bacterial and fungal origins are potentially associated with this biological waste, includ- 
ing Listeria monocytogenes, Aspergillus fumigates (opportunistic pathogen of the throat and nose), Yersinia enterocolitica, Stachybotry s atra, Staphylococcus aureus, A. flavus, Fusarium sp and mycotoxins producing Penicillium sp [17]. Not only that, the persistence of some herbicides and insecticide contaminants in feedstock also influences the quality, marketability, and application of the final product. The detection of chlorinated herbicides, dioxins, organochlorine pesticides, organophosphorus pesticides, polychlorinated biphenyl compounds is just as important.

Nutritional benefits of compost

To perform successful composting diverse feed stocks can be used (Table 2). Decomposition begins with a primary raw mate- rial and other components are supplemented gradually to make the process faster. Organic materials rarely have all the properties that are required for efficient composting, so that the addition of fillers offers a preferred uniqueness to improve quality. Modifications aim to regulate humification, moisture concentration, $\mathrm{C} / \mathrm{N}$ ratio, nitrogen concentration or consistency, while for aeration the filler is the option [20]. Corn stalks, any kind of straw, newsprint, lime, bark flakes, diatomaceous earth, sawdust, wood flakes, fly ash, coal ash and all kinds of leaves are the most common fillers on which composting depends. Aliphatic acids with low molecular weight are found in relatively high concentrations in compost, which comes from straw or wood residues as the starting material.

\begin{tabular}{|c|c|c|c|c|}
\hline Material & $\% \mathrm{~N}$ (dry weight) & $\begin{array}{l}\mathrm{C} / \mathrm{N} \text { ratio (weight } \\
\text { to weight) }\end{array}$ & $\begin{array}{l}\text { \% Moisture content } \\
\text { (wet weight) }\end{array}$ & References \\
\hline \multicolumn{4}{|c|}{ Crop and fruit/veg processing waste } & {$[2,4,10,12,21]$} \\
\hline Corn cobs & $0.4-0.8$ & $56-123$ & $9-18$ & \\
\hline Corn stalks & $0.6-0.8$ & $60-73$ & 12 & \\
\hline Fruit waste & $0.9-2.6$ & $20-49$ & $62-88$ & \\
\hline Apple filter cake & 1.2 & 13 & 60 & \\
\hline Apple pomace & 1.1 & 48 & 88 & \\
\hline Potato tops & 1.5 & 25 & - & \\
\hline Cull potatoes & - & 18 & 78 & \\
\hline Potato processing sludge & - & 28 & 75 & \\
\hline Rice hulls & $0-0.4$ & 113 & $7-12$ & \\
\hline \multicolumn{4}{|c|}{ Straw, hay, silage } & \\
\hline Straw - general & $0.3-1.1$ & $48-150$ & $4-27$ & \\
\hline Straw - oat & $0.6-1.1$ & $48-98$ & - & \\
\hline Straw - wheat & $0.3-0.5$ & $100-150$ & - & \\
\hline Corn silage & $1.2-1.4$ & $38-43$ & $65-68$ & \\
\hline Hay - legume & $1.8-3.6$ & $15-19$ & - & \\
\hline Hay - non legume & $0.7-2.5$ & 32 & - & \\
\hline \multicolumn{4}{|c|}{ Fish and meat processing } & \\
\hline $\begin{array}{l}\text { Blood waste (slaughter house } \\
\text { waste and dried blood) }\end{array}$ & $13-14$ & $3-3.5$ & $10-78$ & \\
\hline Crab and lobster wastes & $1.6-8.2$ & $4.0-5.4$ & $35-61$ & \\
\hline Fish breading crumbs & 2.0 & 28 & 10 & \\
\hline Mixed slaughter house waste & $7-10$ & $2-4$ & - & \\
\hline Poultry carcasses & 2.4 & 5 & 65 & \\
\hline Shrimp waste & 9.5 & 3.4 & 78 & \\
\hline \multicolumn{5}{|l|}{ Wood and paper } \\
\hline News print & $0.06-0.14$ & $398-852$ & $3-8$ & \\
\hline Bark - hard wood & $0.10-0.41$ & $116-436$ & - & \\
\hline Bark - soft wood & $0.04-0.39$ & $131-1,285$ & - & \\
\hline
\end{tabular}

Table 2 
Essential parameters for plant growth are carbon and nitrogen, the former required for energy, growth and later for protein and reproduction. To provide the correct ratio, an additional 25 times carbon is required than nitrogen. The quality is achieved from 20: 1 to 40: 1 of the C/N ratio, however Pan., et al. [24] found promising results with a 25: 1 to $30: 1$ of the $\mathrm{C} / \mathrm{N}$ ratio for the period of time Composting. As the ratio increases, the rate of decomposition decreases, while conversely, there is malodor and nitrogen loss. A lower $\mathrm{C} / \mathrm{N}$ formulation shows a prolonged rise in temperature and indicates poor decomposition and is highly toxic for plants due to the formation of ammonia [25]. For field application, any measured value below 20 can be used as acceptable [26]. However, a low C/N ratio does not indicate the stability of mature compost. The assimilation of compost on soil with an increased $\mathrm{C} / \mathrm{N}$ ratio causes a nitrogen stop and manifests a real nitrogen deficiency for the plant. At the same time, lignin, the main component of the plant cell wall, and its structural complexity reduce the bioavailability of the other cell wall elements, thereby lowering the actual $\mathrm{C} / \mathrm{N}$ ratio.

In such cases, it is often necessary to breakdown lignin, which increases the availability of carbon, speeds up composting, and reduces $\mathrm{N}$ loss. On the other hand polyphenols or insoluble thick tannins attached themselves to either the cell walls or proteins and made them physically or chemically inaccessible for the decomposers [27]. Domínguez and Gómez-Brandón [28] carried out a nutrient dynamic study to check the nitrification effect on vermicomposting and found it to be an indicator of stability. To indicate the degree of vermicompost maturity, the overall increase in the $\mathrm{NO}_{3}^{-}$/ $\mathrm{NH}_{4}^{+}$ratio depends on the reduction in $\mathrm{NH}_{4}{ }^{+}$and the enrichment to $\mathrm{NO}_{3}^{-}$level. Aside from the $\mathrm{C} / \mathrm{N}$ ratio, phosphorous (P) is the most common nutrient from an agricultural point of view and the use of compost affects the solubility/availability of $\mathrm{P}$ significantly. Pan., et al. [24] mentioned that the mineralization of organic phosphates due to the breakdown of organic substances is not considered to be a significant source of $P$ for plants. Inorganic fertilizers and phosphate solubilizing bacteria were added to supply P.

Shak., et al. [10] showed a stimulation of root growth and a nutrient uptake when using vermicompost, which favors a higher yield. Pattnaik and Reddy [29] claimed that, in general vermicompost contains increased and more soluble forms of key nutrients such as nitrogen, phosphorus, potassium, calcium, and magnesium, which are needed for plant growth. To increase plant growth and productivity, micronutrients are essential. In higher concentra- tions, however, they have an unfavorable effect on plant growth [25]. These elements are involved in improving the soil's cation exchange capacity, which makes it easier to hold nutrients and it is directly proportional to the spread of mature compost. Thus, soil organic matter improves soil fertility by changing the soil's physiological properties. Shak., et al. [10] has documented the effects of compost application on soils, which includes nutritional improvement, increasing the concentration of calcium $\left(\mathrm{Ca}^{+2}\right)$, ammonium $\left(\mathrm{NH}_{4}^{+}\right)$, magnesium $\left(\mathrm{Mg}^{+2}\right)$ and potassium $\left(\mathrm{K}^{+}\right)$ions and hold nutrients on these organic matter cation holds.

\section{Amendment of compost and soil physicochemical Attributes}

The Indian economy is dependent on agriculture, with agriculture donating nearly $15 \%$ of gross domestic product (GDP) to explore the possibilities for 'conventional methods' [30]. Herrmann and Lesueur [31], determined that the most important goals of organic farming are: (1) the production of excellent food in sufficient quantities using natural resources, (2) the improvement of the biological cycles for the colonization of soil microorganisms, terrestrial flora, and fauna, (3) maintaining soil productivity and genetic diversity in the experimental system, (4) promoting healthy use through proper maintenance of water resources, (5) balancing crop production and agriculture and (6) reducing pollution. Li., et al. [3] found that a single dose of inorganic nutrients on the soil drastically reduced the microbial load, density of the particles, pore size, and bulk density of the soil. However, the addition of compost immediately improves soil porosity, soil strength, soil compactability, air circulation, soil water supply, water penetration, which is saturated, Hydraulic conductivity, and soil water retention to improve root growth.

A significant reduction in soil density was found during composting of which $4 \%-8 \%$ reduction was only from the top soil. Crop yield is increased as the bulk density of the soil changed indicating a direct relationship between them. On the other hand, a recent study proposed by Sharma., et al. [32] suggested that the soil quality index (SQI) can be kept at 1.10 through the combined use of organic and inorganic fertilizers, but with $100 \%$ application of organic fertilizer it was determined to be 1.08 (SQI). In discussing soil fertility it was found that throughout the arrangement of soil organic matter, nutrients such as nitrogen $(\mathrm{N})$, phosphorus $(\mathrm{P})$, and sulfur (S) are incorporated into the soil, so that the soil can serve as a reservoir for them along with additional nutrients such as $\mathrm{Fe}^{+2}$, $\mathrm{Cu}^{+2}, \mathrm{Zn}^{+2}$, etc. The breakdown of soil organic matter releases nu- 
trients for plant to take up. It is argued that the improvement in soil properties through the application of compost is the function of soil properties including soil texture, moisture conditions, physical properties, and the origin of organic matter. In general, $2-5 \%$ of the soil's organic matter decomposes every year [28].

Long-term composting is essential to achieve more stable effects in which soil property improvement by humus is predominating. A reduced bulk density not only increases root growth, but also a significant uptake of ammonium $\left(\mathrm{NH}_{4}^{+}\right)$and nitrate $\left(\mathrm{NO}_{3}^{-}\right)$ ions were achieved, while the organic substance nitrogen is converted into plant-available mineral form by the mineralization process. Ammonium ions can be directly adsorbed by negatively charged substrates, leached, utilized by plants, or converted into nitrates via nitrification processes through resident microbial colonization in compost and/or vermicompost. On the contrary, some studies have shown that although the ammonium ion content in fresh compost is significantly higher, the survival of Nitrosomonas and Nitrobacter is the main reason for the rapid nitrification, resulting in constant levels of both ion forms $\left(\mathrm{NH}_{4}{ }^{+}\right.$and $\left.\mathrm{NO}_{3}{ }^{-}\right)$during the process towards maturity. Gent., et al. [33] found that in the compost both the $\mathrm{NH}_{4}{ }^{+}$and $\mathrm{NO}_{2}{ }^{-}$concentrations were low, but the $\mathrm{NO}_{3}{ }^{-}$concentrations were increased, which indicates the progress of ammonification and nitrification.

\section{Effect of compost on carbon sequestration and soil erosion}

The application of compost has demonstrated its valuable role not only in the area of plant growth, soil strength, microbial role, reduction of inorganic fertilizers and pesticides, elimination of solid waste, biological remediation, but also justification of climate change through carbon sequestration and greenhouse effects proven [34]. In recent years, mainstream research has focused on the use of compost in combination with crop production and/or field fertilization, which removes carbon dioxide from the atmosphere and stores it back into the soil at a moderately high rate $[35,36]$. This type of organic farming, which combines compost with controlled cultivation, could be an important tool to combat the harmful effects of greenhouse gas emissions. It shows that the use of compost is not only part of intelligent waste management or organic farming, but can also help to overcome the negative effects of global warming. Viglizzo., et al. [36] confirmed that carbon retention in soil is determined by carbon deposition in the root area, where nutrients for respiration and root growth are exchanged when carbon fluxes are added by organic matter.
However, the recent development with LiDAR and an airborne light detection and reading system, aided by drones and satellites, offers better understanding and improved measurement of both atmospheric and terrestrial applied conditions [37]. Large variability in the content of carbon value preserved in the soil is depending on the combined effect of additional and environmental factors. In addition, carbon is considered beneficial in terms of soil health as it can increase water holding capacity, colonization of soil microorganism, nutrient conservation, and organic matter content.

Although soil erosion is a natural process, diverse natural and man-made activities accelerate the process of decay, thereby reducing land productivity and the quality of the environment. Soil erosion can also be controlled through the use of compost which is beneficial in preventing loss of arable land. Erosion has endless adverse effects, and sometimes restoration like hard erosion is too expensive. It can eventually reduce the soil fertility of the land to an unrealizable state. The loss of sediments through erosion and the material they transport cause numerous problems with water quality. Phosphorus and nitrates promotes the eutrophication of water bodies, while heavy metals and organic compounds spoil aquatic habitats and impair water quality. With all of these factors, it is necessary to developed and apply the most appropriate, costeffective land management practices. In addition to traditional methods of combating erosion, researchers are now focusing on new approaches such as land transformation and changing of land occupation [38].

While analyzing the effects of fertilizers, it was found that though compost improvers soil erosion at various stages of development but the single use of compost did not show any significant difference. Saad., et al. [38] found a correlation between the amounts of erosion and nutrient losses when using various compost or mulch substances. $60 \%$ increase in the diameter of the trunk was found compared to the untreated one when a combination of primary pulp and paper mill sludge (PMS) was used. In parallel a low bulk density and a higher cation exchange capacity are the effects of the compost treatment compared to untreated. When lime and its effect were investigated on sewage sludge compost a remarkable improvement in soil $\mathrm{pH}$ in the organic matter and humus content of the soil was observed upon addition.

Effect of compost application on humification

Earlier studies provided information about the valuable effects 
of humic substances (HS) on soil fertility and plant productivity (Figure 3). They influence plant growth, by increasing the diameter and length of the root, the number of leaves, the diameter of the shoot and length as well as the germination of the seeds. Zhou., et al. [39] have reported that $40 \%$ of organic manure substitutions in commercial growing medium offer additional benefits for seed ger- mination, plant growth, and productivity. These positive effects are illustrated by the direct contact of humic substances with metabolic methods. The addition of humic substances not only increases the uptake of nutrients but also increases cell permeability. Humic substances play a crucial role in soil fertilization as they can change plant growth as a growth regulator [3].

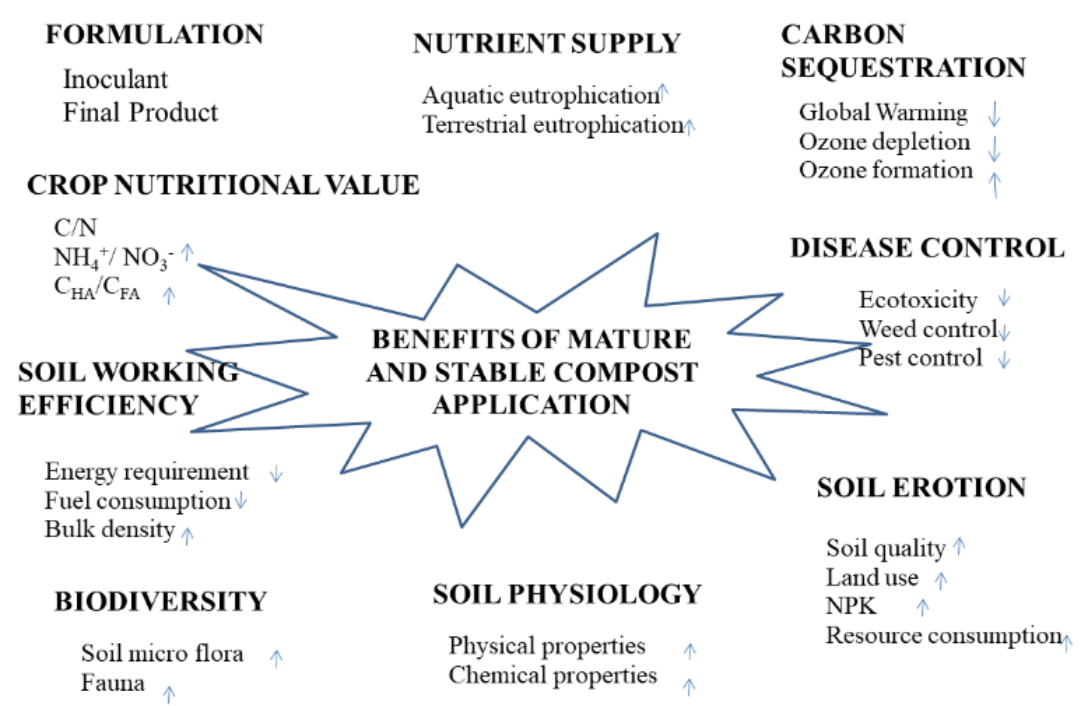

Figure 3: Schematic representation of the benefits of mature and stable compost application. Up arrow ( $\uparrow$ ) indicates increased and down arrow $(\downarrow)$ indicates the decreased activity of various parameters upon compost application.

Many products such as peat, compost, and mulch are used in agricultural practice today to establish organic farming. Products enriched with humic acids have been marketable for grass, horticultural, or plant cultivation for the past few decades. Some plants were found to have a slower growth rate but showing an increased response when treated with compost because of the increase concentration of humic acids and auxin, a hormone that promotes plant growth. As the resident microbial community plays a critical role in reducing monomeric phenolic compounds there is a rapid increase in seed germination as well as plant growth. The microbial mineralization of lignocellulose and biochemical plant processes stimulates the release of phenolic monomers and explained the reduction in concentration.

It has already been reported that precise fillers or suitable supplements played a decisive role in successful decomposition. The type of change can control the progress of the humification; the formation of humic acid (HA), its concentration and its relationship to fulvic acid (FA). Zhou., et al. [39] showed that humification has so far only been dependent on the concentration of humic substances and their components (HA and FA). Composting mechanism in which microbial decomposition of complex organic matter is mainly aimed at the accumulation of humic acid (HA), a valuable parameter which indices not only the maturity of the compost but also the fertility of the soil and increases the harvest yields [40]. The stimulation of root growth, the reproduction of the root hairs, the development of root initiation by humic acids and plant growth promotion has already been described earlier [41]. Though humic substances occur naturally in soil but their concentration increased only after complete decomposition of organic matter.

Although there are only limited reports on the determination of compost maturity, there are no standard methods to assess this [42]. The lack of reliable methods for determining compost matu- 
rity creates problems when using immature compost [43]. There is a lot of literature on the subject; however, there is controversy between the parameters that indicate that compost maturity is still in place [20]. Not only maturity, but also stability is another indication of the degradation of organic material. If the end product mainly contains humic acid, it will not be able to maintain microbial activity and thus achieve stability. Stability is not only an important quality parameter; it can also be used to monitor process performances and to compare between different composting systems. Therefore, the maturity of the finished compost quality now depends on the humic substance concentration (HS). Although Li., et al. [3] found that mature compost is always enriched with high HA, and low FA content.

\section{Role of compost on nutrient uptake and plant growth}

Plant growth depends on the uptake of nutrients by the roots and the rate at which they are provided compared to the concentration. Therefore nutrients in the available forms in the soil are very crucial for the development of the plant. Nishant and Biswas [44] found that this depends entirely on the rate of release of nutrients from the fertilizer into the soil. While varieties of elemental nutrients are required for successful plant growth, the most important nutrients that limit plant growth are considered nitrogen $(\mathrm{N})$ and phosphorus (P). However, productivity is impaired in many agricultural areas with the low content these ions. Thus, soil nutrients with relatively high concentrations of inorganic fertilizer are needed to support global food production [45]. It has been reported that when these nutrients are found limited, overall growth is reduced. On the contrary, the roots are expanded and the uptake of nutrients is facilitated by the microbial colonization. Gent., et al. [33] reported that in soils with a low N supply, the root promotes lateral growth and that growth is suppressed when the condition is reversed.

Plants absorb reactive $\mathrm{N}$ sources from the soil in the form of nitrate $\left(\mathrm{NO}_{3}{ }^{-}\right)$, ammonium, and amino acids from soil which are relatively abundant [33]. Plants can utilize both inorganic and organic nitrogen. Nitrate $\left(\mathrm{NO}_{3}{ }^{-}\right)$and ammonium $\left(\mathrm{NH}_{4}^{+}\right)$ions belong to the first category but amino acids, peptides (di- and tri-peptides), and proteins fall under it later. Not only direct absorption through microbial colonization, in the root surface improves the availability of nutrient. A mutual arbuscular mycorrhizal association is beneficial for capturing $\mathrm{PO}_{4}{ }^{-3}$ and $\mathrm{NO}_{3}{ }^{-}$while symbiotic $\mathrm{N}_{2}$-fixing bacteria convert atmospheric nitrogen into ammonium ion [46]. In order to achieve maximum yield, it is important to have a good balance of all these nutrients during plant development. In addition $\mathrm{N}$ also serves as a signaling molecule that controls seed dormancy, flowering time, vegetative growth, root reproduction, etc.

Under natural conditions, the concentrations of organic and inorganic $\mathrm{N}$ sources in the soil are very heterogeneous and active, which depends on various factors such as physico-chemical properties of the soil, soil microorganisms, and environmental parameters. Since most agricultural soils are free of urea, amino acids, $\mathrm{NH}_{4}^{+}$, peptides, and proteins, supplementing with $\mathrm{NO}_{3}^{-}$with fertilizers, is the most important source of $\mathrm{N}$ for plant growth under aerobic conditions [25]. Although the total concentration of organic $\mathrm{P}$ and inorganic (Pi) in the earth's crust is high, plant growth only depends on the availability of orthophosphates $\mathrm{CH}_{2} \mathrm{PO}_{4}^{-}$and $\mathrm{HPO}_{4}^{-}$ ${ }^{2}$ ), which are found lower in agricultural areas. Alatorre-Cobos., et al. [45] stated that the availability of inorganic P for plant uptake depends entirely on the $\mathrm{pH}$ of the soil, the positive ion concentration, and the rapid microbial conversion from available inorganic to unavailable organic form. Their limiting effect increases the application of Pi fertilizers every year. The higher $\mathrm{P}$ uptake is due to the rock phosphate solubilization by the resident microbial community.

The mechanism of solubilization of Rock Phosphate is based on the secretion of $\mathrm{H}^{+}$and the production of organic acid [47]. Plant roots excreted $\mathrm{H}^{+}$into the rhizosphere, which supports a higher uptake of cations compared to anions. Nishanth and Biswas [44] carried out a kinetic study to examine the effect of plant growth effect upon nutrient availability and they proposed that in pot culture those plants treated with available phosphorus showed higher shoot yield during the developmental stage. Apart from that phosphate-solubilizing microorganisms are involved in the production of organic acids, in particular citric, aketogluconic, oxalic, tartaric, acetic, lactic, gluconic acid, etc. through which mineral phosphates are dissolved and available for the plant [48]. Reyes., et al. [47] found that organic acid anions, together with the $\mathrm{pH}$ reduction, trigger chelation reactions to solubilize rock phosphate. The hydroxyl and carboxyl groups present in organic acids can form a chelate with phosphate-bounded cations $\left(\mathrm{Ca}^{2+}, \mathrm{Fe}^{2+}, \mathrm{Fe}^{3+}\right.$, and $\left.\mathrm{Al}^{3+}\right)$ and initiate their solubilization [49]. Organic anions initiate P mobilization through ligand exchange reactions. Not only that acid phosphatases and phytases of microbial origin play decisive role in the solubilization of rocks [47]. 
Modification of soil biological properties with composts

Organic substances play a key role in improving the biophysical and elementary properties of the soil (Figure 3). Soil architecture is improved either through cationic compounds that hold organic matter and clay together or through microbial colonization that promotes root growth [50]. Most of the composting research has focused on the essential and ionic changes such as respiratory activities, enzyme tests like cellulase, xylanase, glycosidase, proteases, phosphatase, and dehydrogenase, ATP measurements, acetate incorporation into lipids, substrate dependent functional analysis and emissions of nitrous oxide $\left(\mathrm{N}_{2} \mathrm{O}\right)$ and methane $\left(\mathrm{CH}_{4}\right)$ which are considered as indicator of the end of composting [20]. Hultman., et al. [51] explained on the importance of phospholipid fatty acids (PLFAs) studies in order to obtain more detailed information about the changes in the microbial population as well as the total biomass.
Goyal., et al. [52] reported that the enzyme activity gradually amplified during the decomposition, and retained reached its maxima at 30 days. However, Raut., et al. [26] reported maximum productions within 2 weeks after, protease, phosphatase, or aryl sulfate concentration are relatively higher in the initial stages during the initial phases of composting. It has been said that a change in substrate composition leads to a variation in bacterial colonization which influences enzyme activity and the decomposition process. Although the concentration of dissolved organic matter, in the compost is initially very high, it gradually decreases as it matures [1]. Since photosynthesis is negligible, the $\mathrm{CO}_{2}$ concentration can served as an indicator for the microbial load [20]. On the contrary, $\mathrm{CH}_{4}$ is the end product of methanogenesis the anaerobic decomposition process. Certain sub-fractions of PLFAs (Table 3) are also established as taxonomical indicators [51]. In addition, the hydroxy-substituted fatty acids of the lipo-polysaccharides (LPSs) are also useful as indicators for identifying modifications within the microbial community.

\begin{tabular}{|c|c|c|}
\hline Abbreviations & Designation of fatty acids & Indicator for \\
\hline PLFA & Phospholipid fatty acids & Microbial biomass \\
\hline EL-SATFA & Ester-linked saturated fatty acids & Prokarya, Eukarya \\
\hline Straight ch & Straight-chain fatty acids & Eukarya, widespread \\
\hline Cyclopropyl & Fatty acids containing cyclopropyl ring & $\begin{array}{l}\text { Growth conditions, gram negative or positive } \\
\text { bacteria }\end{array}$ \\
\hline Iso-anteiso & Position of methyl branching is iso or anteiso & $\begin{array}{l}\text { Gram-positive or -negative bacteria (Cytopha- } \\
\text { ga, Acetobacter, Flavobacterium) }\end{array}$ \\
\hline Branched chain & $\begin{array}{l}\text { Branched-chain fatty acids (position of methyl branching } \\
\text { is unknown }\end{array}$ & Gram-positive, bacteria, actinomycetes \\
\hline $10 \mathrm{ME}$ & Methyl branching on $10^{\text {th }} \mathrm{C}$ atom & Actinomycetes \\
\hline EL-PUFA & Ester-linked polyunsaturated fatty acid & Eukarya, Cyanobacteria \\
\hline EL-MUFA & Ester-linked monounsaturated fatty acids & $\begin{array}{l}\text { Vaccenic type, bacteria; oleic type, wide- } \\
\text { spread; gram negative bacteria }\end{array}$ \\
\hline EL-HYFA & Ester-linked hydroxy fatty acids & \\
\hline Alpha & Hydroxy substitution at position 2 nearest to carboxyl end & Pseudomonas, gram-negative bacteria \\
\hline Beta & at position 3 nearest to carboxyl end & Thiobacillus \\
\hline Mid chain & Position of hydroxy substitution is unknown & \\
\hline Omega & Hydroxy substitution at aliphatic end & Fungi \\
\hline S & Type of fatty acid unidentified (homologous series) & \\
\hline $\mathrm{Z}$ & Type of fatty acid unidentified (homologous series) & \\
\hline
\end{tabular}




\begin{tabular}{|c|c|c|}
\hline LPS-HYFA & $\begin{array}{l}\text { Hydroxyl substitutedfatty acids localized in outer mem- } \\
\text { brane (LPSs) }\end{array}$ & \\
\hline Alpha & Hydroxy substitution at position 2 nearest to carboxyl end & Gram-negative bacteria \\
\hline Beta & Hydroxy substitution at position 3 nearest to carboxyl end & $\begin{array}{l}\text { Gram-negative bacteria, except Eikenella and } \\
\text { Arthrobacter }\end{array}$ \\
\hline Mid chain & Position of hydroxy substitution is unknown & \\
\hline Omega & Hydroxy substitution at aliphatic end & Plants (cutin, suberin) \\
\hline Decarboxylic & Dicarboxylic fatty acids & \\
\hline S & Type of fatty acid unidentified (homologous series) & \\
\hline $\mathrm{Z}$ & Type of fatty acid unidentified (homologous series) & \\
\hline $4 \mathrm{k}$ & Type of fatty acid unidentified (homologous series) & \\
\hline NEL-UNSFA & Non-ester-linked unsubstituted fatty acids & Clostridium sp. Eukarya (anaerobic bacteria) \\
\hline NEL-HYFA & Non-ester-linked hydroxy-substituted fatty acids & Clostridium sp. Eukarya (anaerobic bacteria) \\
\hline
\end{tabular}

Table 3

Future perspective; formulation and economical importance of composting

Extensive research towards compost development has been carried out worldwide, however numerous scientific and technological question to improve the effectiveness of the process and the excellence of the product remain unanswered. Mainstream research is aimed at improving the degradation stage, adding nutrient, studying the diversity of the microbial population, and increasing the effectiveness of composting processes. The latest trend emphasizes the switch from conventional methods to organic farming in order to protect nature. Ghosh [53] conducted a study on converting inorganic to organic farming to keep production constant. In that study, he claimed that replacing inorganic fertilizers with organic fertilizers is not at all obstructing their family income. Furthermore, the application of organic fertilizers in no way hampers family income. Moreover it can help in rural development and economies with employment, procurement, and trade in organic and inorganic fertilizers. This study has shown that rural development can be promoted through the use of organic farming. The combined use of manure and inorganic fertilizers increases the yield by up to $26 \%$, and the market value increases by up to $40 \%$ compared to the application of chemical fertilizer alone [48]. Thus there has been a significant increase in the economic benefits for farmers when equivalent economic investments are made to improve soil fertility.

The economic profitability of organic farming is also characterized by low pesticide pollution, lower water consumption, control of soil erosion, reduction of carbon emissions and increased biodiversity. Behera., et al. [54] explained that compared to conventional agriculture, natural farming produces similar cultivation variants, but reduces the cost of fertilizer and energy by half. In addition, it has enriched our soil compared to the inorganic amendment. However, Chouichom and Yamao [55] found that the cost of organic farming is $34 \%$ lower than traditional methods without significantly affecting the quality and quantity of product yields. Not only are some new strategies emerging that emphasize the external addition of potential microorganisms to break down complex materials present in the soil in a relatively shorter time in order to obtain high quality compost [56]. But there is no perfect formulation that exists for that and it is clear that each type has its own merits and demerits. However, there are a few key steps that must be carefully measured in the manufacture of vaccines that determine success or the failure.

Farmers can only choose one formulation, which must be inexpensive and easy to use, to ensure that the product can be delivered to the desired plant in the most appropriate way. Hence, only the formulation (whether an inoculum or an end product) is critical, but little attention has been paid to this matter from the past to the present day. Herrmann and Lesueur [31] suggested that the formulation of inoculants is a long-term process that ends with one or more potential isolates, along with a specific carrier such as encapsulated cells, peat, granules, liquids, etc., for protection during storage and transport. A high-quality formulation also provides 
optimal conditions for improving microbial growth in soil, increasing their activities to be profitable when added as inoculum, to increase soil fertility. On the other hand the percentage of N, P and $\mathrm{K}$ is decisive step for the for the compost formulation [54].

\section{Summary}

Green revolution technologies involved increasing the exploitation of agricultural substances to produce high yielding crops that increase the yield per hectare. Since the constant use of chemicals changes the $\mathrm{pH}$ of the soil and creates toxicity, skillful use of chemical fertilizers is required to protect the environment. At the same time waste recycling is required as it breaks down the complex material and returns nutrients to the soil. As mentioned earlier the most stable and tenacious organic carbon fraction ligno-cellulose, from organic waste, limits the composting process by preventing humus formation, which increases soil fertility. In contrast decomposition with Faenia rectivirgula, Saccharomonospora viridis, Streptomyces thermoviolaceus, Thermoactinomyces thalpophilus, T. vulgaris, Bacillus sp, Pseudomonas sp increases the possibilities of lignin degradation. Therefore, complete degradation with these microbes is required to improve the soil condition. The classical theory of lignin degradation suggested route 1(R1 in Figure 1), in which modified lignins are formed, but microbial decomposition by fungi and bacteria mainly follows the other routes (R2-R4 in Figure 1) in which quinone is produced from polyphenol oxidation through the action of several oxidases. Once the decomposition was completed and humic acid was produced the physical, chemical and biological parameters of the soil changed, as evidenced by the analyzing of particle size, texture, particle density, bulk density, dry matter content and the content of non-compostable debris, $\mathrm{pH}, \mathrm{C} / \mathrm{N}$ ratio, total increase of the $\mathrm{NO}_{3}{ }^{-} / \mathrm{NH}_{4}{ }^{+}$ratio, solubilization of phosphate and microbial load (Colony Forming Unit/ml). Plant growth depends on the availability of nutrients, not the concentration in soil that has been taken up by the roots. Because nutrients are limited the overall growth has stopped. Conversion of solid waste to compost, by lignin degrading organism made the end product a rich source of organic material, which facilitates the growth of soil micro flora and enables the continuous supply of the elements essential for plant growth.

\section{Conclusion}

The diversity of crops with elevated nutritional value is the basic need now. At the same time focus is needed on production yield and quality improvement. However, to overcome the deleterious effect of chemical fertilizer on food and fodder has alerted the primary focus of almost all investigating groups to develop urgently a new and competent agricultural system with the use of natural resources. Developments of various cultivars were not supervised thoroughly in the past, due to the limited knowledge on plant metabolism but tools are now available to monitor that. Systems biology has also accelerated to support the yield and crop performance in the field with the help of abundant regulatory elements revealed for several pathways. The purpose of organic agriculture is to supply nutritionally enriched food with the smallest environmental impacts during manufacturing. As mentioned above, humus-rich compost generated by microbial decomposition of organic waste allows the plant to absorb more nutrients. At the same time, it also increases the organic matter content in the soil so that it can be used for longer. Compost affects soil enzyme availability which is directly associated with microbial colonization. The synergistic effect of all the parameters finally increases beneficial microbial community over pathogens that favor plant growth. Since the soil has a complex microenvironment, additional research is needed to get maximum soil fertility and crop productivity in order to address farmers' worries. Novel and successful agricultural service systems along with proper educational guidance will help them execute organic farming properly with an enhancement of farm profit.

\section{Ethics Approval and Consent to Participate}

Not applicable.

\section{Consent for Publication}

Not applicable.

\section{Availability of Data And Materials}

All data generated or analysed during this study are included in this published article.

\section{Supplementary Data}

There is no separate file for supplementary data.

\section{Competing Interests}

The authors declare that they have no competing interests.

\section{Funding}

This research did not receive any specific grant from funding agencies in the public, commercial, or not-for-profit sectors. 


\section{Authors' Contributions}

IP is responsible for conceptualization, resources, validation, visualization and writing the original draft.

\section{Acknowledgement}

I express my gratitude to the Saveetha School of Engineering, Saveetha Institute of Medical and Technical Sciences, Saveetha University, for providing the necessary infrastructure to carry out this work successfully.

\section{Bibliography}

1. Sellami F., et al. "Maturity assessment of composted olive mill wastes using UV spectra and humification parameters". Bioresource Technology 99 (2008): 6900-6907.

2. Saha PK., et al. "Long-term integrated nutrient management for rice-based cropping pattern: Effect on growth, yield, nutrient uptake, nutrient balance sheet, and soil fertility". Communications in Soil Science and Plant Analysis 38 (2007): 579-610.

3. Li Y., et al. "Humic Acid Fertilizer Improved Soil Properties and Soil Microbial Diversity of Continuous Cropping Peanut: A Three-Year Experiment". Nature Scientific Reports 9 (2019): 12014-12022.

4. Sharholy M., et al. "Municipal solid waste characteristics and management in Allahabad, India". Waste Management 27 (2007): 490-496.

5. Xu F and Webb JP. "Tianjin clean-up after explosion”. Canadian Medical Association Journal 187 (2015): E404.

6. Chen M., et al. "Bioremediation of soils contaminated with polycyclic aromatic hydrocarbons, petroleum, pesticides, chlorophenols and heavy metals by composting: applications, microbes and future research needs". Biotechnology Advances 33 (2015): 745-755.

7. Loick N., et al. "Bioremediation of poly-aromatic hyrdocarbon (PAH) contaminated Soil by Composting". Critical Reviews in Environmental Science and Technology 39 (2012): 271-332.

8. Ren X., et al. "Improvement of humification and mechanism of nitrogen transformation during pig manure composting with Black Tourmaline". Bioresource Technology 307 (2020): 123236.

9. Meléndrez M M. "Humic acid: the science of humus and how it benefits soil”. Acres USA Magazine (2012).
10. Shak KPY., et al. "Sustainable reuse of rice residues as feedstocks in vermicomposting for organic fertilizer production". Environmental Science and Pollution Research 21 (2014): 1349-1359.

11. Wang Q., et al. "Improvement of pig manure compost lignocellulose degradation, organic matter humification and compost quality with medical stone". Bioresource Technology 243 (2017): 771-777.

12. Jindo K., et al. "Influence of biochar addition on the humic substances of composting manures". Waste Management 49 (2016): 545-552.

13. Zhang J., et al. "The use of biochar-amended composting to improve the humification and degradation of sewage sludge". Bioresource Technology 168 (2014): 252-258.

14. Jurado MM., et al. "Enhanced turnover of organic matter fractions by microbial stimulation during lignocellulosic waste composting". Bioresource Technology 186 (2015): 15-24.

15. Bohacz J. "Microbial strategies and biochemical activity during lignocellulosic waste composting in relation to the occurring biothermal phases". Journal of Environmental Management 206 (2018): 1052-1062.

16. Hepperly P., et al. "Compost, manure and synthetic fertilizer influences crop yields, soil properties, nitrate leaching and crop nutrient content". Computer Science Utility 17 (2009): 117-126.

17. Bhattacharyya PN and Jha DK. "Plant growth-promoting rhizobacteria (PGPR): emergence in agriculture". World Journal of Microbiology and Biotechnology 28 (2012): 1327-1350.

18. Umsakul K., et al. "Chemical physical and microbiological changes during composting of the water hyacinth". Pakistan Journal of Biological Science 13 (2010): 985-992.

19. Shariati S., et al. "The potential of application of different organic and inorganic carriers in insoluble phosphate solubilizing bacteria (Pseudomonas fluorescens) inoculants production process". International Journal of Agriculture : Research and Review 3 (2013): 176-183.

20. Kutsanedzi F., et al. "Comparisons of Compost Maturity Indicators for two Field Scale Composting Systems". International Research Journal of Applied and Basic Sciences 3 (2012): 713720. 
21. Pan I and Sen SK. "Microbial and physico-chemical analysis of composting process of wheat straw". India Journal of Biotechnology 12 (2013): 120-128.

22. Amir S., et al. "Structural changes in lipid free humic acids during composting of sewage sludge". International Biodeterioration and Biodegradation 55 (2005): 239-246.

23. Grube M., et al. "Evaluation of sewage sludge-based compost by FTIR spectroscopy”. Geoderma 130 (2006): 324-333.

24. Pan I., et al. "Composting of common organic wastes using microbial inoculants". 3 Biotech 2 (2012): 127-134.

25. Krouk G., et al. "Nitrate signaling: adaptation to fluctuating environments". Current Opinion in Plant Biology 13 (2010): 266273.

26. Raut MP., et al. "Microbial dynamics and enzyme activities during rapid composting of municipal solid waste: A compost maturity analysis perspective". Bioresource Technology 99 (2008): 6512-6519.

27. Palm CA., et al. "Organic inputs for soil fertility management in tropical agroecosystems: application of an organic resource database". Agriculture, Ecosystems and Environment 83 (2001): 27-42.

28. Domínguez J., et al. "The influence of earthworms on nutrient dynamics during the process of vermicomposting". Waste Management Research 31 (2013): 859-868.

29. Pattnaik S and Reddy MV. "Nutrient status of vermicompost of urban green waste processed by three earthworm species: Eisenia fetida, Eudrilus eugeniae, and Perionyx excavates". Applied and Environmental Soil Science (2010).

30. Narayanan S. "Organic farming in India: relevance, problems and constraints". Fin Agri, 43 (2005): 16-22.

31. Herrmann L and Lesueur D. "Challenges of formulation and quality of biofertilizers for successful inoculation". Applied Microbiology and Biotechnology 97 (2013): 8859-8873.

32. Sharma KL., et al. "Combined effect of tillage and organic fertilization on soil quality key indicators and indices in alluvial soils of Indo-Gangetic Plains under rainfed maize-wheat system". Archives of Agronomy and Soil Science 61 (2014): 313327.

33. Gent L and Forde BG. "How do plants sense their nitrogen status?” Journal of Experimental Botany 68 (2017): 2531-2539.
34. Vergara SE. "Composting”. In C. A. Zimring, and W. L. Rathje (Eds.), Encyclopedia of consumption and waste: The social science of garbage (2012): 147-150.

35. De Longe MS., et al. "A lifecycle model to evaluate carbon sequestration potential and greenhouse gas dynamics of managed grasslands". Ecosystem 16 (2013): 962-979.

36. Viglizzo EF., et al. "Reassessing the role of grazing lands in carbon-balance estimations: Meta-analysis and review". Science of the Total Environment 661 (2019): 531-542.

37. Keenan TF and Williams CA. "The terrestrial carbon sink". Annual Review of Environment and Resources 43 (2018): 219243.

38. Saad R., et al. "Assessment of land use impacts on soil ecological functions: development of spatially differentiated characterization factors within a Canadian context". International Journal of Life Cycle Assessment 16 (2011): 198-211.

39. Zhou Y., et al. "Evaluation of humic substances during cocomposting of food waste, sawdust and Chinese medicinal herbal residue". Bioresource Technology 168 (2014): 229-334.

40. Khalid M., et al. "Influence of bio-fertilizer containing beneficial fungi and rhizospheric bacteria on health promoting compounds and antioxidant activity of Spinacia oleracea L". Botanical Studies 58 (2017): 35-43.

41. Canellas LP., et al. "Chemical properties of humic matter as related to induction of plant lateral roots". European Journal of Soil Science 63 (2012): 315-324.

42. Mokhtari M., et al. "Evaluation of stability parameters in invessel composting of municipal solid waste". Iranian Journal of Environmental Health Science and Engineering 8 (2011): 325-332.

43. Ofosu-Budu GK and Hogarh JN. "Harmonizing procedures for the evaluation of compost maturity in two compost types in Ghana". Resources Conservation and Recycling 54 (2010): 205209.

44. Nishanth D and Biswas DR. "Kinetics of phosphorus and potassium release from rock phosphate and waste mica enriched compost and their effect on yield and nutrient uptake by wheat (Triticum aestivum)". Bioresource Technology 99 (2008): 3342-3353.

Citation: Ieshita Pan. "Compost Soil Amendment: An Approach to Enhance Crop Productivity by Improving Soil Physiology". Acta Scientific Microbiology 5.2 (2022): 88-103. 
45. Alatorre-Cobos F., et al. "Genetic determinants of phosphate use efficiency in crops". In Genes for Plant Abiotic Stress (Eds MA Jenks and AJ Wood). Wiley-Blackwell, Oxford (2009): 143165.

46. Bouguyon E., et al. "Nitrate sensing and signaling in plants". Seminars in Cell and Developmental Biology 23 (2012): 648654.

47. Reyes I., et al. "Phosphate-solubilizing microorganisms isolated from rhizospheric and bulk soils of colonizer plants at an abandoned rock phosphate mine". Plant Soil 287 (2006): 69-75.

48. Kearney S., et al. "Forty percent revenue increase by combining organic and mineral nutrient amendments in Ugandan smallholder market vegetable production". Agronomy for Sustainable Development 32 (2012): 831-839.

49. Alori ET., et al. "Microbial phosphorus solubilization and its potential for use in sustainable agriculture". Frontiers in Microbiology 8 (2017): 971.

50. Gao M., et al. "Evaluation of stability and maturity during forced aeration composting of chicken manure and sawdust at different/N ratios". Chemosphere 78 (2010): 614-619.

51. Hultman J., et al. "Determination of fungal succession during municipal solid waste composting using a cloning-based analysis". Journal of Applied Microbiology 108 (2010): 472-487.

52. Goyal S., et al. "Chemical and biological changes during composting of different organic wastes and assessment of compost maturity". Bioresource Technology 96 (2005): 1584-1591.

53. Ghosh N. "Reducing dependence on chemical fertilizers and its financial implications for farmers in India". Ecology Eco 49 (2004): 149-162.

54. Behera KK., et al. "Organic farming history and techniques, in Sustainable Agriculure Reviews, ed. by Lichtfouse E. Springer, Berlin (2012): 287-328.

55. Chouichom S and Yamao M. "Organic fertilizer use in northeastern Thailand: an analysis of some factors affecting farmers' attitudes". in Sustainable Agriculture Development, ed. by Behnassi M, Shahid SA and D'Silva J. Springer, Berlin (2011): 185-196.

56. Gaind S. "Effect of fungal consortium and animal manure amendments on phosphorus fractions of paddy-straw compost". International Biodeterioration and Biodegradation 94 (2014): 90-97.

\section{Assets from publication with us}

- Prompt Acknowledgement after receiving the article

- Thorough Double blinded peer review

- Rapid Publication

- Issue of Publication Certificate

- High visibility of your Published work

Website: www.actascientific.com/

Submit Article: www.actascientific.com/submission.php

Emaill us: editor@actascientific.com

Contact us: +919182824667 